\title{
Comparison of Chemical Properties of Food Products Processed by Conventional and Ohmic Heating*
}

\author{
R. PEREIRA, M. PEREIRA, J. A. TEIXEIRA, and A. A. VICENTE \\ Centro de Engenharia Biológica, Universidade do Minho, Campus de Gualtar, 4710 - 057 Braga, Portugal \\ e-mail: rpereira@deb.uminho.pt
}

Received 1 April 2006; Revised 6 September 2006; Accepted 10 September 2006

\begin{abstract}
The effect of ohmic and conventional heat processing of different food products on their chemical and physical parameters was studied. Depending on the food being analysed, parameters such as $\mathrm{pH}$, total solids, ash, titratable acidity, ascorbic acid, total sugars, total fatty acids, total phenolic compounds, and anthocyanins content were determined before and after ohmic and conventional pasteurization techniques and the results were compared using one-way analysis of variance. In goat milk samples treated by ohmic technology the $\mathrm{pH}$ value (6.58) and total fatty acids content in milk fat (86.5 mass \%) were comparable to those found in milk treated by conventional process, however, ohmically treated samples presented a lower content of lactic acid, $0.13 \%$. In cloudberry jam samples treated by ohmic technology the results of some of the main parameters tested, such as total sugar content 46.1 mass $\%$, ascorbic acid content 2.83 mass \%, and titratable acidity 6.01 mass \% (as citric acid) did not show significant differences when compared with samples treated by conventional technology.
\end{abstract}

Keywords: ohmic heating, goat milk, cloudberry jam, total fatty acids, ascorbic acid

\section{INTRODUCTION}

In recent years, the world's food industry has focused increasing attention on electrical techniques of food processing. Ohmic heating is one of these techniques that involve the passage of an alternating electrical current through a food product, allowing generation of heat inside of it in agreement with the Joule's law. Indeed, the food behaves as a resistor in an electrical circuit [1]. Presently, most liquid foods are preserved commercially by ultra-high-temperature or high-temperature short-time processes. However, the thermal processing of fruit purees and jams, for example, is traditionally difficult, essentially due to their rheological properties. The problem is aggravated when fruit particles are present in the slurry, as in the case of fruit purees to be incorporated in yoghurts. In fact, in order to process them fully to meet food safety requirements, an over-processing of the liquid phase is necessary. This is mainly due to the heat transfer mode used (conduction) leading to important losses both in nutritional and organolep- tic terms. The use of conventional heat exchangers is not possible and scraped surface devices are normally used instead. The contact of the slurry with a hot surface is promoted and mixing is achieved by means of rotating blades. These are responsible for mechanical damage to the fruit particles affecting the final quality of the product and diminishing its acceptability to the consumer. Maintenance of such scraped surface heat exchangers is also more expensive than that of the most usual plate-and-frame or shell-and-tube options.

It is widely accepted that raw milk cheeses are among the most appreciated for their unique flavour and taste, having an excellent market value, but it is also known that they present a safety problem to the consumer due to the use of raw milk. However, traditional pasteurization implies the loss of nutritional and organoleptic qualities of the end product, be it milk itself or the cheese made from it, due to the high shear stresses imposed on milk during heat treatment in plate-and-frame heat exchangers, normally employed to heat-treat the milk to be used in cheese production. High shear stress destroys the fat globules and frees

*Presented at the 33rd International Conference of the Slovak Society of Chemical Engineering, Tatranské Matliare, 22-26 May 2006. 
their fatty acid content, which rapidly oxidizes, producing off-odours and off-flavours. This effect is particularly true in the milk of small ruminants (sheep and goat). A safer product is obtained, then, but its properties are no longer compatible with those demanded for such high market value products.

In general, the absence of hot surface in ohmic heating devices reduces fouling problems and thermal damage to the product. Therefore, a highquality product with minimal structural, nutritional, or organoleptic changes could be manufactured within a short operating time. The potential applications of this technique in food industry are very wide and include blanching, evaporation, dehydration, and fermentation [2]. Ohmic heating can be accomplished in a continuous in-line heater for cooking and sterilization of viscous and liquid food and also for heating of high-acid food products such as tomato-based sauces prior to hot filling, with considerable benefits in product quality. Other potential applications include rapid heating of liquid food products that are difficult to heat by conventional technologies. For liquid whole eggs, extremely rapid rates of heating enable higher pasteurization temperatures to be applied, with consequent increase in refrigerated shelf life, without inducing coagulation or excessive denaturation of the constituent proteins [3]. According to Icier and Ilicali [4] ohmic heating is used in milk and fruit juice processing and currently is used in Japan and the United Kingdom for the processing of whole fruits and production of syruped fruit salad, respectively. Although the technology of ohmic heating appears to be promising and highly effective, there is little information concerning the effects of this technique on specific food products compared to conventional pasteurization [5, 6]. According to Assiry et al. [7] the electrochemical aspects of ohmic processes are restricted to few studies. The aim of this work is to characterize chemically some food products before and after ohmic heating and to perform an identical characterization after a conventional heating, comparing the effects of both processes in terms of food's chemical properties and subsequent quality.

\section{EXPERIMENTAL}

All the samples of goat milk and cloudberry jam were obtained from jam and goat cheese producers. Chemical and physical characterization of both food products was performed using unprocessed samples, which served as a control. Samples pasteurized using ohmic and conventional heating were taken from the same production lot.

In order to get reliable results $5 \mathrm{~kg}$ of unprocessed samples were collected just before entering the conventional and ohmic heating units. Alternatively, $1 \mathrm{~kg}$ of the thermally treated samples was taken from the production line right after leaving the pasteurization unit at five different times (in the case of a continuous process) or five randomly chosen volumes (batch process) for subsequent analysis.

For the ohmic processing of goat milk and cloudberry jam was used a continuous ohmic heater comprising one teflon heating section (240 $\mathrm{mm}$ long and 90 mm wide) with two electrodes constituting side walls of the heating section. The electrodes were made of high titanium content stainless steel and their surface in contact with food was coated with platinum to minimize corrosion. Temperature measurements were conducted using teflon-coated copper-constantan thermocouples (Omega Engineering, Stamford, CN) inserted inside the heating chamber. Ohmic processing of goat milk and cloudberry jam was done by passing the food products through the heating section of the ohmic heater via a monopump designed to minimize damage of the pumped highly viscous or particulate food. Inside the heating section voltages of $40 \mathrm{~V}, 140 \mathrm{~V}$, and $240 \mathrm{~V}$ of alternating current were applied across the two electrodes. An isolating transformer was used to provide safe working environment and to adjust the potential supplied to the ohmic heater according to the conductivity of food product processed. During processing the desired voltage was kept constant while the current varied between $1 \mathrm{~A}$ and $10 \mathrm{~A}$.

Conventional batch or continuous processing of the chosen products was carried out using either scrapped surface heater or plate exchange heater. Goat milk was pasteurized (conventionally and ohmically) at the temperature of $75^{\circ} \mathrm{C}$ with a contact time of $15 \mathrm{~s}$. Cloudberry jam was hot filled at $95^{\circ} \mathrm{C}$ in both heat treatments. Prior to thermal treatment, all samples delivered by the producers were kept at $-18^{\circ} \mathrm{C}$. In the case of semisolid cloudberry jam containing $35 \%$ of cloudberry fruit, $58 \%$ of sugar, and $3 \%$ of pectin further preparation was necessary. The samples (100 $\mathrm{g}$ in triplicate) were homogenized and smashed using a Moulinex Commercial Turbo Blender. The pits of cloudberry fruits were drained off before centrifuging (5 min at $10000 \mathrm{~min}^{-1}$ ) to gain the fruit juice. The homogenates were kept at $4^{\circ} \mathrm{C}$ until their use.

\section{Analysis}

Measurements of $\mathrm{pH}$ and titratable acidity were performed according to the Official Methods of Analysis of AOAC [8] using a pH-meter. The titratable acidity was estimated by the sample titration using standard $0.1 \mathrm{~mol} \mathrm{~L}^{-1}$ solution of $\mathrm{NaOH}$. The results were expressed as lactic and citric acid content in goat milk and cloudberry jam, respectively.

Total solids and ash content in food samples were determined by weighing in a dish with washed sea sand (Panreac ref. No. 211160). Milk and jam samples were evaporated and dried to a constant total solid mass at $103-105^{\circ} \mathrm{C}$. Then, it was ignited and burned at 550 $\pm 50{ }^{\circ} \mathrm{C}$ to a constant mass [8]. 
The content of ascorbic acid in cloudberry jam was estimated using HPLC. Homogenized sample for this analysis was prepared by contacting $6 \mathrm{~g}$ of cloudberry jam with $20 \mathrm{~mL}$ of $4.5 \%$ metaphosphoric acid. Prepared mixture was centrifuged at $4000 \mathrm{~min}^{-1}$ for 15 min at $20^{\circ} \mathrm{C}$ and the supernatant was filtered through $0.45 \mu \mathrm{m}$ cellulose prior to its analysis using a Jasco 880-PU intelligent HPLC pump equipped with a Jasco 870-UV intelligent UV-VIS detector and a Jasco AS2057 Plus intelligent autosampler. The mobile phase was $5 \mathrm{mmol} \mathrm{L}^{-1}$ sulphuric acid in ultrapure water with the flow rate of $0.7 \mathrm{~mL} \mathrm{~min}^{-1}$ and the detection wavelength was $245 \mathrm{~nm}$. All samples were run in triplicate and the linearity of detector response was determined ranging from 0.02 to $0.08 \mathrm{~g} \mathrm{~L}^{-1}$ with a $10 \mu \mathrm{L}$ injection volume. The ascorbic acid peak was identified on the sample chromatogram by its retention time according to chromatograms of the standard solutions. The peak areas were integrated and checked for interference or substances other than ascorbic acid eluting at the same retention time.

Similarly, the amount of soluble sugars was determined via HPLC analysis of the cloudberry jam homogenate. For this purpose $6 \mathrm{~g}$ of jam was added to 20 $\mathrm{mL}$ of ultrapure water and centrifuged at $1000 \mathrm{~min}^{-1}$ for $5 \mathrm{~min}$ at $20^{\circ} \mathrm{C}$. Aliquots of supernatant were filtered through a $0.2 \mu \mathrm{m}$ (CA-PC $30 \mathrm{~mm}$ ) cellulose acetate membrane prior to their analysis. Glucose, fructose, and sucrose in the cloudberry jam samples were tentatively identified by the retention time and quantified by the corresponding peak areas of standard solutions. All samples were run in triplicate.

Total soluble phenolics were determined using the Folin-Ciocalteu reagent according to the method of Slinkard and Singleton [9] using gallic acid as a standard.

The total anthocyanin content was estimated using the $\mathrm{pH}$ differential assay proposed by Giusti et al. [10] and Fuleki and Francis [11]. Sample absorbance was measured at $520 \mathrm{~nm}$ and $700 \mathrm{~nm}$ in buffer solutions at $\mathrm{pH}=1.0$ and $\mathrm{pH}=4.5$, respectively. The resulting value of absorbance was obtained using the following equation

$$
A=\left(A_{520}-A_{700}\right)_{\mathrm{pH}=1.0}-\left(A_{520}-A_{700}\right)_{\mathrm{pH}=4.5}
$$

with a molar absorption coefficient of cyanidin-3glucoside (C3G) of 29600 .

The amount of fatty acids was determined using GC by comparing the response obtained for the food samples with that of standard fatty acid methyl esters (FAMEs). Analysis of fatty acids in goat milk samples consisted of lipid extraction and preparation of their corresponding methyl esters. Extraction of lipids in solution was done according to the method of Bligh and Dyer [12]. FAMEs were prepared using sodium methylate $\left(0.5 \mathrm{~mol} \mathrm{~L} \mathrm{~L}^{-1}\right)$ and sulphuric acid in methanol (5\%) according to Canada [13]. Analyses were performed on a CP 9001 gas chromatograph (Chrompack) equipped with a split injection port, flame ionization detector, and TR-WAX capillary column $(30 \mathrm{~m} \times 0.32 \mathrm{~mm} \times 0.25 \mu \mathrm{m}$, Teknokroma $)$ equivalent to a CP-SIL 52CB. The temperature of both the injector and detector was $250^{\circ} \mathrm{C}$. The initial oven temperature was set to $150^{\circ} \mathrm{C}$, after 2 min it was increased to $220^{\circ} \mathrm{C}$ at a heating rate of $10^{\circ} \mathrm{C} \mathrm{min}^{-1}$, and then maintained at this value for $20 \mathrm{~min}$. The samples $(1 \mu \mathrm{L})$ were injected manually using the hot injection technique. For calibration FAMEs were prepared from analytical standards, i.e. stock solutions of free fatty acids (C4:0- C18:2). Individual fatty acids were quantified by the internal standard technique, using methyl ester of tridecanoic acid (C13:0) as an internal standard.

If applicable (at least five experiments), the results are presented as mean value \pm standard deviation (SD). The results of chemical characterization of unprocessed and pasteurized samples using ohmic and conventional treatments were compared on the basis of the analysis of variance (ANOVA) in combination with Tukey's test as post hoc analyses. All were calculated using the SPSS software package (version 14.0, SPSS Inc., Chicago, IL). A significance level of $p<$ 0.05 was considered statistically significant.

\section{RESULTS AND DISCUSSION}

\section{Goat Milk}

The results of chemical analysis $(\mathrm{pH}$, titratable acidity, total solids, ash, and fatty acids content) of

Table 1. Properties of Conventionally $(A)$ and Ohmically $(B)$ Treated as well as Unprocessed $(C)$ Goat Milk

\begin{tabular}{lccc}
\hline \multirow{2}{*}{ Property } & \multicolumn{3}{c}{ Samples } \\
\cline { 2 - 4 } & $A$ & $B$ & $C$ \\
\hline $\mathrm{pH}$ & $6.59 \pm 0.03$ & $6.58 \pm 0.05$ & $6.58 \pm 0.06$ \\
Titratable acidity content/mass \% & $0.132 \pm 0.004$ & $0.126 \pm 0.005$ & $0.134 \pm 0.005$ \\
Total solids content/mass \% & $14.6 \pm 0.1$ & $14.9 \pm 0.1$ & $14.5 \pm 0.1$ \\
Ash content/mass \% & $1.32 \pm 0.06$ & $1.11 \pm 0.03$ & $1.04 \pm 0.06$ \\
Total fatty acids content/mass \% & $88.2 \pm 4.7$ & $86.5 \pm 7.0$ & $93.1 \pm 12.8$ \\
\hline
\end{tabular}


Table 2. Content of Individual Fatty Acid Methyl Esters in Conventionally $(A)$ and Ohmically $(B)$ Treated as well as Unprocessed (C) Goat Milk

\begin{tabular}{|c|c|c|c|}
\hline \multirow{2}{*}{ Fatty acid } & \multicolumn{3}{|c|}{ Content/mass \% } \\
\hline & Sample $A$ & Sample $B$ & Sample $C$ \\
\hline Butyric (C4:0) & $2.23 \pm 0.52$ & $2.26 \pm 0.66$ & $1.84 \pm 0.33$ \\
\hline Caproic (C6:0) & $1.90 \pm 0.15$ & $1.81 \pm 0.22$ & $1.63 \pm 0.32$ \\
\hline Caprylic (C8:0) & $1.90 \pm 0.10$ & $1.73 \pm 0.19$ & $1.62 \pm 0.34$ \\
\hline Capric (C10:0) & $6.38 \pm 0.30$ & $5.71 \pm 0.72$ & $5.56 \pm 1.07$ \\
\hline Lauric (C12:0) & $3.06 \pm 0.12$ & $2.80 \pm 0.33$ & $2.88 \pm 0.38$ \\
\hline Myristic (C14:0) & $7.15 \pm 0.19$ & $6.87 \pm 0.65$ & $7.41 \pm 0.89$ \\
\hline Palmitic (C16:0) & $24.53 \pm 0.65$ & $25.16 \pm 1.92$ & $27.89 \pm 0.89$ \\
\hline Stearic (C18:0) & $12.15 \pm 1.08$ & $12.08 \pm 1.09$ & $13.35 \pm 4.04$ \\
\hline Oleic (C18:1) & $25.05 \pm 1.96$ & $24.38 \pm 2.37$ & $26.73 \pm 4.55$ \\
\hline Linoleic (C18:2) & $3.81 \pm 5.11$ & $3.70 \pm 0.50$ & $4.15 \pm 0.64$ \\
\hline
\end{tabular}

processed and unprocessed goat milk are presented in Table 1. In the case of unprocessed samples, the $\mathrm{pH}$, titratable acidity, represented by the amount of lactic acid, and the total solids content were within the normal range for fresh goat milk [14, 15], however, the content of ash was slightly higher (1.04\% $\pm 0.06 \%)$. This difference can be explained based on the fact that the content of ash, which is one of the major soluble components regulating the osmotic pressure of milk, can be subjected to modifications during the lactation period [16]. The results obtained by analyzing the milk samples processed by ohmic heating were similar to those obtained for goat milk samples unprocessed and processed by conventional heating. According to statistical analysis, the values of above-mentioned chemical parameters of processed and unprocessed milk samples did not differ significantly from each other $(p>0.05)$. Mean content of individual FAMEs, obtained by GC analysis and the respective ranges of variation in the samples of unprocessed and processed milk (both conventionally and ohmically) are given in Table 2 . In the case of unprocessed goat milk, the most abundant FAME was that of palmitic acid $((27.89 \pm 0.89)$ mass $\%)$, followed by oleic $((26.73 \pm 4.55)$ mass \%), stearic $((13.35 \pm 4.04)$ mass $\%)$, myristic $((7.41 \pm 0.89)$ mass $\%)$, and capric $((5.56 \pm 1.07)$ mass \%) acids. The overall content of these fatty acids accounted for $87.0 \%$ of the total mass of FAMEs in unprocessed milk fat. Similarly, the samples of goat milk treated by ohmic heating showed that palmitic, oleic, stearic, myristic, and capric acids presented about $85.8 \%$ of the total mass of FAMEs in the milk fat. The composition of goat milk treated by ohmic heating was comparable $(p>0.05)$ to that of unprocessed milk and conventionally treated milk, in which palmitic, oleic, stearic, myristic, and capric acids also represent $85.4 \%$ of the FAMEs overall content. The FAMEs concentration profiles estimated in this study correlate well with the results presented in $[17,18]$.

On the other hand, production of quality goat milk depends upon nutritional supply of animals [19]. A direct comparison with literature data is quite difficult because the conditions, e.g. breed, lactation period, and number of samples analyzed, are not always specified. Furthermore, the samples were treated differently and the extraction and transesterification procedure varied from case to case.

\section{Cloudberry Jam}

$\mathrm{pH}$ Values of the samples $A, B$, and $C$ showed to be statistically different from each other $(p<0.05)$, however, similar to those found in literature [20]. In samples processed by ohmic heating the total solids $((40.0 \pm 0.6)$ mass \%), ash $((0.24 \pm 0.02)$ mass \%), ascorbic acid $((2.83 \pm 0.14) \mathrm{mg}$ per $100 \mathrm{~g}$ of sample), phenolic compounds $((154.2 \pm 13.3) \mathrm{mg}$ per $100 \mathrm{~g}$ of sample), and anthocyanins $((0.36 \pm 0.06) \mathrm{mg}$ per 100 $\mathrm{g}$ of sample) were similar to those obtained for conventionally processed jam (Table 3 ).

According to Thiem [21], the main phenolic compound in cloudberries is ellagic acid, the content of which was estimated to be $160 \mathrm{mg}$ per $100 \mathrm{~g}$ of seedless dry mass of fruits [22]. This value is comparable with the total phenolics content found in all samples of cloudberry jam investigated in the present study. On the other hand, the measured content of anthocyanins was substantially lower than that published by Kähkönen et al. [23], probably due to the lower recovery of these compounds from the cloudberry jam samples. The experiments confirmed that the heat treatment reduced significantly the concentration of thermolabile compounds. Therefore, the unprocessed jam presented higher content of anthocyanins and citric and ascorbic acids, than the jam samples processed either by ohmic or conventional heating. Furthermore, the analysis showed that the overall content of sugars in the jam samples processed by ohmic ((46.11 \pm 2.33$)$ mass \%) and conventional ((49.90 \pm 5.96$)$ mass \%) heating was slightly higher compared to that found in unprocessed jam samples (Table 4). 
Table 3. Properties of Conventionally $(A)$ and Ohmically $(B)$ Treated as well as Unprocessed $(C)$ Cloudberry Jam

\begin{tabular}{lccc}
\hline \multirow{2}{*}{ Property } & \multicolumn{3}{c}{ Samples } \\
\cline { 2 - 4 } & $A$ & $B$ & \multicolumn{2}{c}{$C$} \\
\hline $\mathrm{pH}$ & $3.83 \pm 0.03$ & $3.65 \pm 0.10$ & $3.37 \pm 0.06$ \\
Titratable acidity content/mass \% & $6.18 \pm 0.08$ & $6.01 \pm 0.01$ & $39.5 \pm 0.08$ \\
Total solids content/mass \% & $39.5 \pm 0.3$ & $40.0 \pm 0.6$ & $0.22 \pm 0.03$ \\
Ash content/mass \% & $0.22 \pm 0.03$ & $0.24 \pm 0.02$ & $0.66 \pm 0.08$ \\
Anthocyanins content/(mg per 100 g of sample) & $0.35 \pm 0.04$ & $0.36 \pm 0.06$ & $144.5 \pm 8.2$ \\
Total phenolics content/(mg per 100 g of sample) & $146.7 \pm 6.9$ & $154.2 \pm 13.3$ & $3.08 \pm 0.10$ \\
Ascorbic acid content/(mg per 100 g of sample) & $3.01 \pm 0.22$ & $2.83 \pm 0.14$ & $36.40 \pm 3.09$ \\
Total sugars content/mass \% & $49.90 \pm 5.96$ & $46.11 \pm 2.33$ & \\
\hline
\end{tabular}

Table 4. Content of Individual Sugars in Conventionally $(A)$ and Ohmically $(B)$ Treated as well as Unprocessed $(C)$ Cloudberry Jam

\begin{tabular}{lccc}
\hline \multirow{2}{*}{ Sugar } & \multicolumn{3}{c}{ Content/mass $\%$} \\
\cline { 2 - 4 } & Sample $A$ & Sample $B$ & Sample $C$ \\
\hline Glucose & $10.30 \pm 0.23$ & $10.81 \pm 0.27$ & $3.76 \pm 0.28$ \\
Fructose & $10.23 \pm 0.23$ & $10.75 \pm 0.25$ & $3.59 \pm 0.25$ \\
Sucrose & $25.95 \pm 0.49$ & $25.81 \pm 0.59$ & $27.55 \pm 1.86$ \\
\hline
\end{tabular}

Concentration of glucose and fructose was similar $(p>0.05)$ in the samples processed conventionally $(A)$ and using ohmic heating $(B)$. Sucrose was the most abundant sugar in all jam samples, representing about 55 mass \% of the total sugars content, as it is added by the producer to reduce the water content in jam [24]. The amount of sugars in the unprocessed samples was lower than that found in the heat-processed samples. The exception was sucrose probably due to the fact that it was not hydrolyzed to glucose and fructose yet. Factors such as the duration of exposure to high temperatures, the degree of acidity, or the $\mathrm{pH}$ of the mixture must be considered in order to control the amount of inverted sugar produced during the jam boiling [25].

In general and concerning the parameters studied, the results of chemical analysis indicate that the technology based on ohmic heating provides products with chemical properties similar to those of the products obtained by conventional treatment.

\section{REFERENCES}

1. de Halleux, D., Piette, G., Buteau, M.-L., and Dostie, M., Canadian Biosystems Engineering/Le génie des biosystèmes au Canada 47, 3.41 (2005).

2. Castro, I., Teixeira, J. A., Salengke, S., Sastry, S. K., and Vicente, A. A., Innovative Food Science and Emerging Technologies 5, 27 (2004).

3. Parrott, D. L., Food Technol. 46, 68 (1992).

4. Icier, F. and Ilicali, C., Food Res. Int. 38, 1135 (2005).

5. Leizerson, S. and Shimoni, E., J. Agric. Food Chem. 53,3519 (2005).
6. Icier, F. and Ilicali, C., Eur. Food Res. Technol. 220, 406 (2005).

7. Assiry, A., Sastry, S. K., and Samaranayake, C., J. Appl. Electrochem. 33, 187 (2003).

8. Official Methods of Analysis of AOAC (Association of Official Analytical Chemists):International Official Methods, 16th Edition, Volume II - Food Composition, Additives, Natural Contaminants. Supplement March 1996.

9. Slinkard, K. and Singleton, V. L., Am. J. Enol. Vitic. 28, 49 (1977).

10. Giusti, M. M., Rodriguez-Saona, L. E., and Wrolstad, R. E., J. Agric. Food Chem. 47, 4631 (1999).

11. Fuleki, T. and Francis, F. J., J. Food Sci. 33, 78 (1968).

12. Bligh, E. G. and Dyer, W. J., Can. J. Biochem. Phys. 37, 911 (1959).

13. Canada, J. S., PhD. Thesis. Universidad Extramadura, Cáceres, Spain, 2001.

14. Todaro, M., Scatassa, M. L., and Giaccone, P., Ital. J. Anim. Sci. 4, 403 (2005).

15. Kanwal, R., Ahmed, T., and Mirza, B., Asian J. Plant Sci. 3, 300 (2004).

16. Keskin, M., Avşar, Y. K., Biçer, O., and Güler, M. B., Turk. J. Vet. Anim. Sci. 28, 531 (2004).

17. Kondyli, E. and Katsiari, M. C., Int. J. Dairy Technol. 55, 57 (2002).

18. Posati, L. P. and Orr, M. L., Agriculture Handbook No. 8, USDA-ARS, p. 77. Consumer and Food Economics Institute, Washington DC, 1976.

19. Greppi, G. F., Ciceri, A., Pasquini, M., Falasch, U., and Enne, G., in Proceedings of IDF-Seminar on Production and Utilization of Ewe's and Goat's Milk, p. 47. Crete, Greece 1995.

20. Suutarinen, M., PhD. Thesis. Helsinki University of Technology, Espoo, Finland, 2002. 
21. Thiem, B., Biol. Lett. 40, 3 (2003).

22. Häkkinen, S. H., Heinonen, M., Kärenlampis, S., Mykkänen, H., Ruuskanen, J., and Törrönen, R., Food Res. Int. 32, 345 (1999).

23. Kähkönen, M. P., Hopia, A. L., and Heinonen, M., J. Agric. Food Chem. 49, 4076 (2001).
24. Ponting, J. D., Watters, G. G., Forrey, R. R., Jackson, R., and Stanley, W. L., Food Technol. 20, 1365 (1966). 25. Molyneux, F., Process Biochem. 6, 17 (1971). 